\title{
Dr. Gautam Parghi
}

Cite as: Can Urol Assoc J 2018 Jan. 15. Epub ahead of print. http://dx.doi.org/10.5489/cuaj.5176

Published online January 15, 2018

The CUA was sorry to hear of the passing of Dr. Gautam Parghi, who died peacefully on September 28, 2017 after a brief hospitalization. He is survived by his wife Krishna Parghi, his children Amit (Aiten) and Ira (Sujit), and his grandchildren Jaya, Noah, Akhil and Nina.

Practicing in his beloved city of Kamloops, Dr. Gautam's compassion and generosity of spirit will be remembered fondly by the many patients whose lives he touched. He has been described as a loving husband and father, a doting grandfather, and a proud and loyal Kamloopsian with endless enthusiasm. He loved ice cream, single malt, good music, and bad jokes.

He will be keenly missed and always remembered.

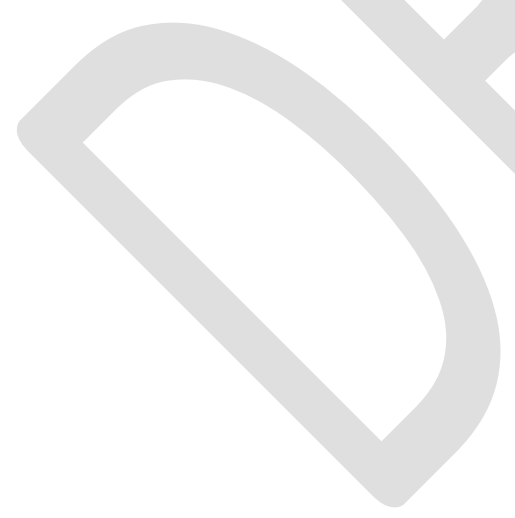

